
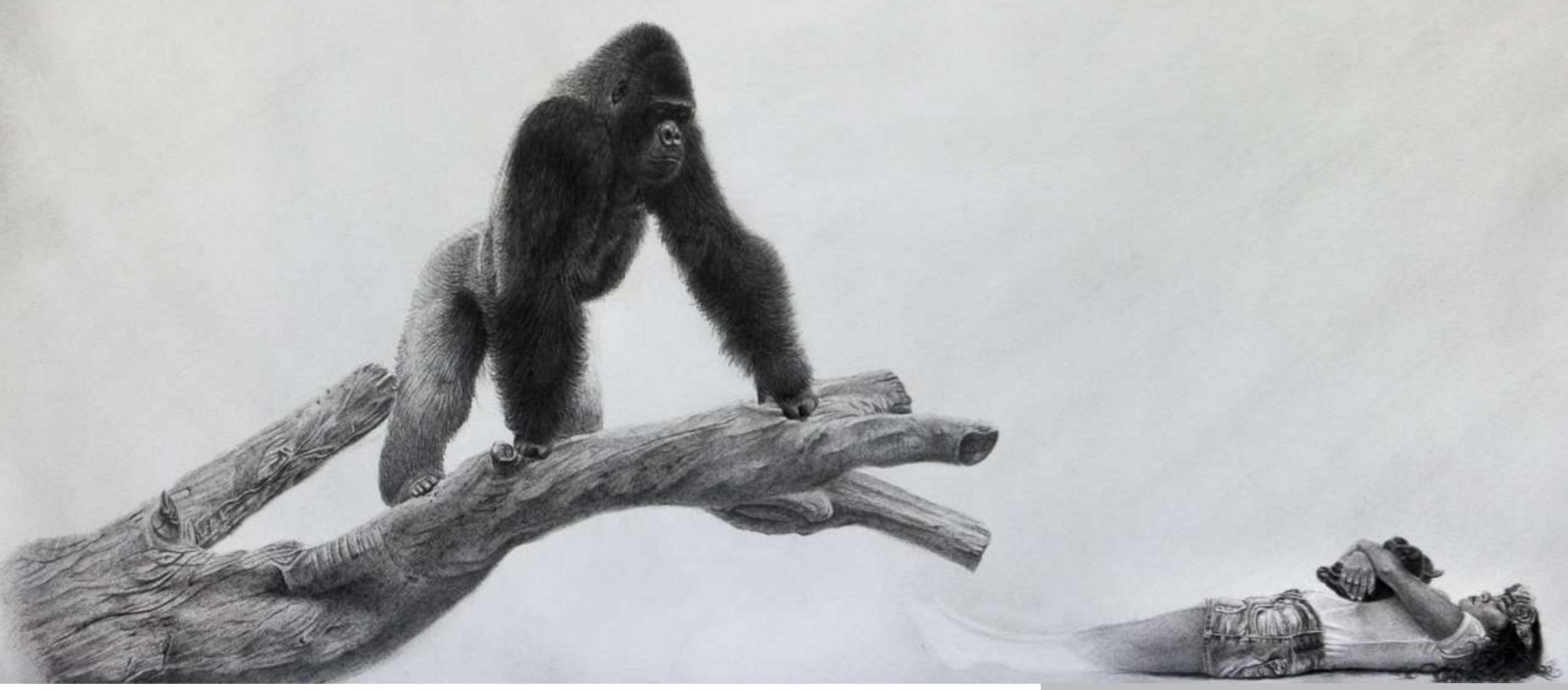

\title{
Sin título
}

De la serie Un viaje hacía el origen

Grafito sobre papel

$22,8 \times 48 \mathrm{~cm}$

2019

Medellín 


\title{
Secularismo político en Chile a partir de los enfoques de Robert Audi y de Cecile Laborde
}

\author{
Cristóbal Bellolio (Chile)*
}

\section{Resumen}

Este artículo explora si Chile puede considerarse secular bajo dos enfoques alternativos: el enfoque de «separación institucional» de Robert Audi y el reciente «enfoque de desagregación» de Cecile Laborde. Respecto del marco de Audi, se sostiene que el Estado chileno respeta el principio libertario, cumple solo parcialmente los requisitos del principio igualitario y está en deuda respecto al principio de neutralidad. Para el poder político chileno, la religiosidad y la ausencia de religiosidad no son valoradas de la misma manera. Con respecto al marco propuesto por Laborde, el Estado chileno cumple, en general, los requisitos de su secularismo mínimo. Subsisten, sin embargo, áreas problemáticas, especialmente cuando los funcionarios estatales emplean razones religiosas no accesibles en el foro legislativo, violando lo que Laborde Ilama el Estado justificable, y cuando el Gobierno utiliza formas de establecimiento simbólico que pueden afectar un estatus cívico igualitario, violando lo que Laborde Ilama el Estado inclusivo.

\section{Palabras clave}

Teoría Política; Secularismo; Religión; Estado; Iglesia; Chile.

Fecha de recepción: febrero de 2019 • Fecha de aprobación: junio de 2019

\section{Cómo citar este artículo}

Bellolio, Cristóbal. (2019). Secularismo político en Chile a partir de los enfoques de Robert Audi y de Cecile Laborde. Estudios Políticos (Universidad de Antioquia), 56, pp. 222-247. DOI: 10.17533/udea.espo.n56a10

\footnotetext{
* Abogado. Magíster en Jurisprudencia y Teoría Política. Doctorado en Filosofía Política. Profesor e investigador de la Escuela de Gobierno, Universidad Adolfo Ibáñez, Chile. Correo electrónico: cristobal.bellolio@uai.cl - Orcid: 0000-0002-7547-7773 - Google Scholar: https://scholar.google.es/ citations?hl=es\&user=8L8S57cAAAAJ
} 


\title{
Political Secularism in Chile from Robert Audi's and Cecile Laborde's Approaches
}

\begin{abstract}
This article explores whether the Chilean State might be considered secular from two alternative approaches: Robert Audi's «institutional separation», and Cecile Laborde's recent «disaggregation approach». Regarding Audi's framework, the study claims that the Chilean State fulfils the libertarian principle, partially meets the requirements of the egalitarian principle, but it does not respect the principle of neutrality, for religiosity and its absence are not valued in the same way by the Chilean political power. Regarding Laborde's framework, the study shows that the Chilean State meets, in general, the requirements of her "minimum secularism» standard. However, some difficulties become evident when state officials employ religious non-public reasons in the legislative forum, thus, violating what Laborde calls the "Justifiable State," as well as when the government uses forms of symbolic establishment that might affect the equal civic status, thus violating what Laborde calls the "Inclusive State.»
\end{abstract}

\section{Keywords}

Political Theory; Secularism; Religion; State; Church; Chile. 


\section{Introducción}

En las dos últimas décadas, Latinoamérica ha experimentado un progresivo proceso de secularización cultural. Mientras en 1995 80\% de la población se declaraba católica, en 2017 solo lo hizo el 59\%. En Chile, específicamente, los autodeclarados católicos bajaron de 74\% a $45 \%$ en el mismo lapso de tiempo. Solo en Honduras, Nicaragua y Panamá el catolicismo registró una caída más pronunciada. Sin embargo, a diferencia de lo que ocurre en otros lugares del continente, donde el descenso del catolicismo se compensa parcialmente con el aumento de la población evangélica, el segmento que más crece en Chile es aquel que no declara «ninguna religión»: sube de 7\% en 1995 a 35\% en 2017 (Latinobarómetro, 2018, enero). En resumen, la Iglesia Católica chilena ha perdido su hegemonía histórica. Sigue siendo la afiliación religiosa mayoritaria, pero ahora debe compartir el espacio de influencia con otras denominaciones y expresiones no-religiosas. Este trabajo, sin embargo, no indaga sobre el proceso de secularización cultural en Chile, sino que examina si acaso el Estado chileno puede ser considerado secular o laico desde un punto de vista político.

[224] Esta es una distinción importante, ya que por secularización la filosofía analítica — particularmente, la teoría política liberal- entiende el proceso a través del cual la sociedad abandona las manifestaciones tradicionales de la fe, mientras que por secularismo se entiende su dimensión estrictamente política, esto es, cómo las instituciones del Estado actúan con independencia del poder religioso. Así, por ejemplo, Charles Taylor (2007) aborda el problema de la secularización de la sociedad occidental y luego, junto a Jocelyn Maclure (2011), aborda el problema de la separación institucional entre Estado e Iglesia, es decir, del secularismo político. ${ }^{1}$ Para todos los efectos relevantes, este artículo entiende que Estado secular y Estado laico son términos intercambiables.

Nominalmente, el Estado chileno se separó de la Iglesia católica a partir del ordenamiento constitucional de $1925 .^{2}$ Sin embargo, son muchas las áreas donde los discursos, rituales y privilegios religiosos se expresan

\footnotetext{
${ }^{1}$ Para una introducción al tratamiento del secularismo político en la teoría política contemporánea, véase Rajeev Bhargava (2006).

${ }^{2}$ Para un análisis histórico, tanto del proceso de secularización social como del progresivo secularismo político que experimentó Chile en la segunda mitad del siglo XIX y que concluyó con la separación del Estado y la Iglesia en la Constitución de 1925, véase Sol Serrano (2008).
} 
en la esfera pública. En esa línea, este artículo interroga si acaso tiene Chile un Estado secular.

Para responderla, se utilizan dos enfoques o marcos de análisis propios de la teoría política liberal. El primero corresponde a la teoría de separación institucional entre Iglesia y Estado desarrollado por el filósofo estadounidense Robert Audi a finales de la década de 1980. El segundo corresponde a la estrategia de desagregación de la religión que ha propuesto recientemente la teórica política francesa Cecile Laborde. Así, en la primera sección se presentan los elementos centrales de la teoría de Audi. La segunda sección examina si acaso Chile tiene un Estado secular a partir del cumplimiento de los requisitos de su teoría. La tercera sección presenta los elementos centrales de la teoría de Laborde. La cuarta examina el caso chileno a la luz de esta teoría. En otras palabras, dos secciones teóricas y dos secciones que tienen por finalidad evaluar si Chile tiene un Estado secular a partir de estos marcos de análisis.

\section{La teoría de separación institucional entre Estado e Iglesia}

Tres criterios normativos enumera Audi (1989; 2000) para evaluar la efectiva separación institucional entre Estado e Iglesia. Al primero le denomina principio libertario, pues establece el derecho de todas las personas de profesar el culto que estimen conveniente dentro de los límites del orden público. Este derecho no solo incluye la dimensión de la conciencia individual, sino que se extiende a la práctica colectiva. Habrá casos en los cuales dichos límites serán controvertibles. Por ejemplo, el consumo ritual de peyote por parte de tribus nativas en Norteamérica o de marihuana por parte de grupos rastafari que la utilizan como una vía de exploración espiritual. Ambas drogas son normalmente consideradas ilegales, pero estos colectivos recurren al poder político que suspenda la aplicación general de la ley cuando dichas sustancias son utilizadas en un contexto religioso. Otros casos complejos de libertad de culto se dan cuando ciertos grupos religiosos reclaman el derecho de hacer uso del espacio público de una forma que implica abierto proselitismo. Sin perjuicio de estos casos difíciles, en lo medular, el cumplimiento del principio libertario compromete al poder político a respetar las distintas creencias de la población. Es un criterio de laissez faire religioso. En este sentido, los individuos gozan de libertad religiosa, entendiendo libertad en clave negativa: es un ámbito 
de no-interferencia. Su fundamento se encuentra en la idea de tolerancia que históricamente ha definido al pensamiento liberal: el gobernante se abstiene de establecer qué filiaciones y prácticas religiosas tienen cabida en la sociedad. Cumpliendo ciertos requisitos básicos, todas son permitidas.

El segundo criterio es el principio igualitario. Establece que el Estado no puede hacer diferencias en el trato que otorga a las distintas denominaciones religiosas. En teoría, la autoridad política podría permitir la libertad de culto en sus diversas formas - respetando el principio libertario-, pero al mismo tiempo imponer ciertas cargas o gravámenes, o bien granjear subsidios o beneficios a algunas confesiones religiosas y no a otras. Es decir, aun en un marco de libertad religiosa negativa, el Estado podría distribuir sus recursos políticos, materiales y simbólicos en forma desigual entre las distintas confesiones que pueblan su territorio. El caso más extremo son aquellas teocracias que, si bien permiten algunas expresiones de disidencia religiosa, establecen al mismo tiempo que solo los fieles de la religión oficial pueden acceder a ciertas posiciones de poder. También se viola el principio igualitario, aunque apenas formalmente, en aquellos Estados democráticos donde existe una religión oficial de Estado, como en Reino Unido y Argentina. En ambos existe libertad religiosa. Aun así, el monarca de Reino Unido es siempre la cabeza de la Iglesia de Inglaterra, mientras la constitución argentina establece que «el Gobierno federal sostiene el culto católico, apostólico y romano» (Ley 24430, Capítulo primero, Artículo 2).

El principio igualitario, en cambio, impone al poder político el deber de tratar a todas las expresiones religiosas con igualdad. En un Estado secular ideal, según Audi, no hay espacio para privilegios ni aun al pretexto de una larga relación histórica entre el poder político y alguna de las Iglesias que pueblan su territorio. Tampoco es pretexto la capacidad de presión política que tienen algunas comunidades. Es común que confesiones religiosas hegemónicas intenten que la legislación blinde su posición aventajada, limitando los espacios a la competencia. Pero el Estado secular no puede exhibir favoritismos al respecto, ni en términos de legislación ni en términos simbólicos. Lo hace, por ejemplo, cuando establece que solamente los miembros de ciertas Iglesias pueden acceder a ciertos cargos en el sector público o cuando se conceden exenciones tributarias que se aplican solo a ciertas organizaciones religiosas en desmedro de las demás. El principio igualitario encuentra su fundamento en la promesa liberal de no discriminación. 
Finalmente, el tercer principio que ofrece Audi es el principio de neutralidad: el poder político debe tratar a la religiosidad de la misma manera en que trata a la no-religiosidad. En teoría, un Gobierno podría entregar a todas las confesiones y sectas religiosas un trato igualitario, y al mismo tiempo podría discriminar contra aquellas personas que no se consideran parte de ninguna. La diferencia entre el principio igualitario y el principio de neutralidad es que el segundo exige que la imparcialidad estatal impere no solo entre denominaciones religiosas, sino entre la religiosidad y la ausencia de ella. Mientras el principio igualitario prescribe que el poder político no debe poner sus recursos al servicio de la promoción de ningún credo particular, el principio de neutralidad prescribe que tampoco puede hacerlo respecto del valor que subyace a todos los credos religiosos.

Sobre esta distinción, Brian Barry (2002) analiza el caso de Carlos, príncipe de Gales. Para congraciarse con las comunidades musulmanas de Reino Unido, Carlos declaró que, en el evento de ascender al trono, cambiaría el título tradicional de Defender of the Faith —el cual Ilevan los monarcas británicos desde tiempos de Enrique VIII en alusión al anglicanismo- por Defender of Faiths, en plural. Los ateos, agnósticos y no-creyentes quedarían fuera de la protección real, aunque sea en un sentido simbólico. El principio de neutralidad, en cambio, exige que la autoridad política no haga diferencia entre unos y otros. Es un criterio no exento de problemas, en el entendido de que la frontera entre religiosidad y no-religiosidad no es clara. Hay muchos grises entre el teísmo convencional —cristianismo, judaísmo, islam- y el ateísmo militante que niega la existencia de cualquier divinidad. ¿En qué categoría clasificamos al deísta que cree en la participación de una fuerza sobrenatural en el origen cósmico, pero que luego se retira de la escena y no vuelve a intervenir?, ¿o al panteísta que cree que la naturaleza misma es la expresión auténtica de la divinidad? Por otro lado, el poder político tiene obvias dificultades para definir los contornos del fenómeno y la experiencia religiosa (Sullivan, 2005; Laborde, 2017; Precht, 2006). Sin perjuicio de los casos difíciles, en lo medular, el principio de neutralidad coloca a la población no creyente en el mismo plano de reconocimiento público que a la población creyente.

El cumplimiento de estos tres principios permite sostener, en el enfoque de Audi, que el poder político está institucionalmente separado del poder religioso. A continuación, se abordará en qué situación se encuentra el sistema político chileno al ser evaluado con estos estándares. 


\section{El Estado chileno frente a la teoría de separación institucional}

Respecto del principio libertario, es razonable contestar afirmativamente. En Chile, la libertad de consciencia está garantizada constitucionalmente. Así, el artículo 19 numeral $6 .^{\circ}$ asegura a todas las personas «la manifestación de todas las creencias y el ejercicio libre de todos los cultos que no se opongan a la moral, a las buenas costumbres o al orden público». Es decir, el orden constitucional reconoce explícitamente el derecho de todo ciudadano a profesar la religión que estime conveniente. Nadie debería sufrir coerción estatal por ello. Los problemas aparecen al precisar los límites de esta garantía.

En 2012, una pareja que realizaba rituales chamánicos con ayahuasca en la comuna de Pirque fue absuelta por los tribunales de justicia. Si embargo, el fallo no se concentró en su libertad religiosa sino en el silencio de la ley frente al tráfico y consumo de la sustancia. Hasta hoy, grupos de consumidores de cannabis continúan batallando en la arena legislativa y en las cortes por su derecho a lo que ellos entienden como una experiencia de carácter espiritual. Tampoco pudieron invocar con éxito el principio libertario

[228] los seguidores chilenos de la llamada secta Moon, que vieron cancelada su personalidad jurídica en 2005. La Iglesia de la Unificación —su verdadero nombre- reconoce la existencia de una deidad universal e identifica en el coreano Sun-Myung Moon la segunda venida de Cristo. El Estado chileno juzgó que algunas de sus prácticas eran incompatibles con la moral y las buenas costumbres, pues -entre otras cosas- celebraban matrimonios colectivos entre desconocidos y aprobaban rituales de sanación violentos.

Estos casos introducen la pregunta de si acaso la vocación paternalista del Estado - el cual interviene en nombre de la salud física y emocional de los fieles respectivos- debe prevalecer por sobre la libertad de culto, por radical o extravagante que el culto sea. Si la adscripción a una determinada institución religiosa es voluntaria, ¿qué legitimidad tiene la autoridad para impedir sus prácticas cuando estas se llevan a cabo entre adultos autónomos que no dañan a terceros ajenos a la práctica? Una parte de la literatura liberal sugiere que lo único que debe y puede hacer el poder político es asegurar una especie de «derecho de salida» (Kukathas, 1992) para quienes quieran abandonar la asociación religiosa por las razones que sean. En ese sentido, de acuerdo con el espíritu del principio libertario, no le corresponde al Estado evaluar la moralidad intrínseca de un determinado culto religioso. 
Respecto del cumplimiento del principio igualitario, el Estado chileno ha avanzado en las últimas décadas. A partir del acuerdo político alcanzado con la Santa Sede en 1925, se reconoció en forma exclusiva a la Iglesia católica como personalidad jurídica de derecho público. En 1972, el mismo estatus fue conferido por ley a la Iglesia ortodoxa vinculada al Patriarcado de Antioquía. La Ley 19638 de 1999 —más conocida como Ley de Cultosextendió este estatus a otras entidades religiosas reconocidas por el Estado. ${ }^{3}$ La principal diferencia entre la Iglesia católica y la Iglesia ortodoxa, por un lado, y el centenar de Iglesias protestantes que accedieron a la categoría de personalidad jurídica de derecho público gracias a esta ley, por el otro, es que las segundas debieron iniciar un procedimiento administrativo para obtener el reconocimiento del Estado, debiendo someter sus estatutos a la aprobación del Ministerio de Justicia y quedando su estatus legal sujeto a una eventual cancelación por sentencia judicial. También se han observado algunas diferencias en materia de autonomía para crear órganos religiosos y en cuanto al régimen de administración de bienes (Salinas, 2004; Precht, 2006).

Sin perjuicio deestas asimetrías menores, al abandonar la «interpretación reduccionista» que buscaba limitar la personalidad jurídica de derecho público a la Iglesia católica romana y a la Arquidiócesis ortodoxa, le ley chilena avanza en materia de paridad (Precht, 2006). Si bien algunos sostienen que la Iglesia católica latinoamericana se ha opuesto sistemáticamente a que las demás denominaciones mejoren sus estatus, promoviendo medidas para dificultar el desempeño de las Iglesias protestantes (Gill, 2006), lo cierto es que, al menos en Chile, se ha «nivelado hacia arriba»: en lugar de quitarle al catolicismo sus privilegios, se han extendido sus beneficios, lo que está en sintonía con el principio igualitario de Audi. Así, por ejemplo, todos los templos dedicados al culto - sin distinción alguna, una vez que son reconocidos por el Estado-gozan de similares exenciones tributarias.

Más allá del ámbito estrictamente legal, es posible identificar un ámbito de desigualdades simbólicas. El Ejército de Chile es un buen ejemplo. Aunque se trata de una institución históricamente asociada al credo católico,

\footnotetext{
${ }^{3}$ Esta ley deja constancia expresa de lo que ya había sostenido la mayoría de la comisión elaboradora de la Constitución chilena de 1980, esto es, que todas las confesiones religiosas —y no solo la católica y la ortodoxa - gozaban de personalidad jurídica de derecho público una vez reconocidas por el Estado. Dicha constancia expresa parece haber sido necesaria. Hasta la entrada en vigor de la Ley de Cultos, parte significativa de la doctrina chilena negaba la personalidad jurídica de derecho público de los entes religiosos no católicos (Silva y Silva, 1991; Corral, 1998).
} 
el censo de 2002 reveló que uno de cada cuatro de sus integrantes profesaba algún tipo de fe evangélica. En 2005, cuando 44 soldados perecieron en la tragedia del volcán Antuco, el Ejército organizó los respectivos servicios fúnebres de acuerdo con el rito católico, lo que fue rechazado por más de la mitad de los deudos. Se aceleraron entonces las gestiones para incorporar un capellán evangélico que pudiera atender las demandas espirituales del contingente, lo que ocurrió en 2008 (Escobar, 2009, octubre 23). El Ejército, a través de sus canales oficiales de comunicación y redes sociales, continúa refiriéndose a la Virgen del Carmen como «Patrona y Generalísima de las Fuerzas Armadas de Chile» y "guía espiritual de los soldados» (Ejército de Chile, 2019, julio 19). Sin embargo, algunos estudios concluyen que la Armada de Chile es la rama que presenta mayor influencia del catolicismo en su normativa interna y procesos de formación (Diaz, 2006). En varias de estas instituciones, incluyendo a Carabineros de Chile, se realizan periódicamente ceremonias de bautismo, primera comunión y confirmación para sus efectivos, en las cuales los altos oficiales suelen manifestar que dicho camino espiritual contribuye a la formación profesional. En resumen, las Fuerzas Armadas de Chile no han estado a la altura del principio igualitario.

La Moneda, el Palacio de Gobierno, tuvo solo un capellán católico [230] hasta 2001, fecha en la que incorporó a su primer capellán evangélico. Más tarde sumó a un representante del judaísmo. También se trata de un avance si se trata de asegurar mayor igualdad simbólica entre las distintas confesiones religiosas. La pregunta es si dichos avances obedecen a una convicción normativa o bien son políticamente prudenciales: ¿se hubieran incorporado capellanes evangélicos a La Moneda si los últimos censos de población no hubieran registrado un aumento en la feligresía de dicha comunidad religiosa? Lo mismo cabe preguntarse respecto de la institución del «Día nacional de la Iglesias Evangélicas y Protestantes», feriado creado en 2008 bajo el gobierno de Michelle Bachelet. Sin capacidad de presión política, es difícil que se vean capellanes musulmanes, Hare Krishna o mormones en el Palacio de Gobierno. El problema de las consideraciones meramente cuantitativas y de realpolitik es que legitiman un trato desigual entre religiones mayoritarias y minoritarias.

El principio igualitario, en cambio, no está constreñido por consideraciones numéricas ni depende de la capacidad de presión política de las distintas denominaciones. Por el contrario, dicta que el Estado tiene el deber de tratar a todas las entidades religiosas de la misma forma, sin 
importar el tamaño o la influencia de la comunidad. El principio igualitario se satisface si todas las entidades religiosas son ascendidas al goce de los mismos beneficios, o bien si todas descienden de categoría ante los ojos del Estado. Si algunas denominaciones tienen presencia formal en los organismos públicos, entonces todas deben tenerla. Es una regla de justicia simple: todas o ninguna. Esto no implica desconocer que las exigencias filosóficas son difíciles de conciliar con la praxis política. Efectivamente, nadie reclama por la ausencia de un representante del caodaísmo o del unitarismo universalista en el Palacio de Gobierno. Además, algunas denominaciones religiosas menos tradicionales carecen de una figura de autoridad que pueda representarlos ante los organismos públicos, tal como lo hacen sacerdotes, pastores y rabinos. En otros casos, la misma comunidad religiosa rechazaría el espacio. Por ejemplo, es improbable que los testigos de Jehová o los cuáqueros tengan interés en una capellanía castrense tratándose de confesiones declaradamente pacifistas.

En algunos casos, no es fácil determinar qué se considera religión para efectos de equiparar el trato estatal: ¿son religiones el New Age, el druidismo celta, el culto satánico o la devoción popular Maradoniana en Argentina? El filósofo Daniel Dennett (2006), por ejemplo, ha sugerido que la religión es un sistema social cuyos participantes creen en uno o más seres sobrenaturales cuya aprobación es buscada. El problema de esta conceptualización es que deja fuera muchas expresiones de espiritualidad que suelen considerarse religiosas, como el budismo. Esto confirma la dificultad que tiene el poder político si se trata de definir con precisión los contornos del fenómeno religioso con propósitos regulatorios.

Si bien el Estado de Chile cumple en materia de libertad religiosa mientras presenta significativos avances en materia de igualdad religiosa, los resultados en materia de neutralidad entre creyentes y no creyentes no son buenos. El principio de neutralidad se refiere a la imparcialidad que deben exhibir las instituciones políticas respecto a los distintos tipos de espiritualidad que manifiestan los ciudadanos, incluyendo la ausencia de espiritualidad. El Estado chileno sería neutral si fuese indiferente respecto de las creencias religiosas de su población, tal como lo es respecto de sus orientaciones sexuales o sus preferencias culinarias. En diversas instancias, sin embargo, sus autoridades han expresado una idea distinta. En diciembre de 2011, a propósito de las celebraciones religiosas — Navidad y Janucáque se llevaban a cabo en edificios públicos, el entonces presidente 
Sebastián Piñera señaló: «Este es un gobierno que no es neutral con respecto de la espiritualidad, que cree firmemente, al menos como presidente y como creyente, aunque pecador, en el valor de la espiritualidad, y por eso buscamos promoverla y hablar de Dios» (Cooperativa.cl, 2011, diciembre 23).

En 2013, la candidata oficialista Evelyn Matthei fustigó el programa de gobierno de su contendora Michelle Bachelet, específicamente respecto de la promesa de terminar con las referencias religiosas en los juramentos prestados ante los poderes del Estado. Frente a una multitud de fieles evangélicos, señaló: «Ustedes saben que Dios pone a los gobernantes y Dios los saca, pero Él espera que ustedes le ayuden [...]. Si el día de mañana tenemos un país absolutamente laico no lloren cuando no han tratado de parar este movimiento, cuando podían hacerlo con su voto» (Cooperativa. cl, 2013, noviembre 25).

Matthei no ganó, pero las promesas de Bachelet tampoco se hicieron efectivas, las referencias religiosas no desaparecieron. Con el regreso de Piñera al poder en 2018 no se han registrado avances conforme al principio de neutralidad. En su visión, el Estado debe limitarse a asegurar libertad

[232] religiosa e igualdad entre los distintos credos. Piñera considera legítimo -e incluso imperativo, de acuerdo con sus convicciones morales- utilizar recursos públicos para promover la religiosidad en cuanto tal. Es decir, no hace proselitismo exclusivo a favor de su fe católica, hace proselitismo ecuménico. El mensaje que envía Piñera es que el poder político es indiferente respecto del credo escogido, en la medida que se escoja uno. A la inversa, el mensaje es que quienes no profesan ningún tipo de creencia religiosa -ateos, agnósticos, librepensadores, no creyentes en general- no son dignos de la misma valoración. En otras palabras, su gobierno piensa que es mejor creer en algo que no creer en nada.

Sebastián Piñera es pródigo en referencias a Dios, una práctica a la cual la literatura anglosajona denomina God Talk. En Estados Unidos, la mayoría de los presidentes hace alusiones a Dios en sus discursos, aunque la práctica se intensifica cuando los republicanos están en el poder, como fue el caso con George W. Bush (Lincoln, 2006). En los últimos años, en Latinoamérica, Dios ha desfilado en la boca de los gobernantes de izquierda, como Hugo Chávez, Rafael Correa y el tándem Daniel Ortega y Rosario Murillo. En el caso del presidente chileno, Piñera ha sugerido que 
sus menciones a Dios son genéricas (Bellolio, 2014). Es decir, se estaría refiriendo a todas las divinidades, Ilámese Dios, Jehová, Alá, entre otros. Aquello es consistente con el principio igualitario, pero no lo es respecto del principio de neutralidad, ya que una porción relevante de la población no cree en ninguna de esas divinidades. Esta parte de la población puede estimar que la idea de una deidad personal, como la describía Albert Einstein, es intelectualmente infantil además de moralmente castradora (Hitchens, 2009). En conclusión, según el principio de neutralidad, el gobierno chileno falta el debido respeto a sus ciudadanos no creyentes cuando insiste en la promoción de la creencia religiosa, cualquiera que esta sea, por estimarla superior a la no-creencia religiosa.

Para despejar dudas, el principio de neutralidad también sería violado si el gobierno incentivara el ateísmo o una actitud hostil frente a la religiosidad. La separación institucional que describe Audi apunta a un Estado secular, no antirreligioso. Secular, en el sentido liberal, equivale a no tomar partido por ningún set de creencias metafísicas respecto de la existencia o inexistencia de un orden trascendental o sobrenatural. No implica censurar el fenómeno religioso en ninguna de sus expresiones ni transformarlo en blanco de hostilidades sistemáticas, como lo fue en la esfera de influencia de la Unión Soviética en el siglo xx. El principio de neutralidad, por tanto, no debe ser interpretado como parte de una asonada laicista. Lamentablemente, este fue el argumento que varios actores políticos chilenos esgrimieron para oponerse a una reforma al reglamento del Congreso que propuso en 2016 la diputada comunista Camila Vallejo.

En Chile, las sesiones de la Cámara Baja todavía se abren «en nombre de Dios». Vallejo propuso reemplazar dicha alusión religiosa por una fórmula más secular: que las sesiones se abran «en representación del pueblo de Chile». El proyecto fue interpretado por algunos como una agresión a la religión (Emol, 2016, octubre 11). Pero es una objeción fuera de lugar. Vallejo no pide que las sesiones se abran en nombre de Darwin o advirtiendo sobre la inexistencia del dios cristiano. Pide omitir la referencia teísta y en su lugar aludir a lo que tienen en común: su calidad de representantes. En cualquier caso, sobreviven en la legislación chilena varios resabios similares, especialmente en materia de juramentos ante los poderes del Estado. ${ }^{4} \mathrm{De}$

${ }^{4}$ En diciembre del 2013, la Cámara de Diputados aprobó eliminar la referencia religiosa del juramento
que, según disposición del Código Orgánico de Tribunales (COT), deben realizan los jueces y auxiliares
de la administración de la justicia al asumir su cargo. Al respecto, el COT establece la fórmula «ijuráis 
acuerdo con el principio de neutralidad, todas estas fórmulas deben ser derogadas si son establecidas como obligatorias.

En resumen, de los tres criterios que establece Robert Audi (1989; 2000) para evaluar el grado de separación institucional entre Estado e Iglesia, Chile cumple satisfactoriamente el principio libertario, avanza en la dirección correcta respecto del principio igualitario, mientras sigue en deuda con relación al principio de neutralidad. Bajo este enfoque, el Estado de Chile es parcialmente secular.

\section{La estrategia de desagregación de la religión}

La teórica política Cecile Laborde ha dedicado los últimos años a investigar si acaso la religión debe ser tratada como un fenómeno especial en el marco de una filosofía política liberal. Algunos sostienen que la religión es acreedora de un tratamiento especialmente favorable por sus particulares características (McConnell, 2000). Otros piensan que debe ser combatida en el espacio público, principalmente desde la tradición francesa de laïcité. Laborde (2017) se pregunta específicamente cuál es el tipo de secularismo que un Estado liberal requiere para ser considerado como tal.

[234] Es decir, se distancia del proyecto de Audi, puesto que no indaga por los criterios que determinan el grado de secularismo político de un Estado, sino por aquellos que le bastan al liberalismo. Dicho de otra manera, se pregunta en qué momento la influencia de la religión en la vida pública comienza a transformarse en un problema para los principios liberales. Son dos enfoques alternativos y eventualmente complementarios, en la medida de que ambos aspiran a trazar los contornos del secularismo, los que una vez establecidos pueden ser aplicados a distintas realidades institucionales para su respectiva evaluación.

La tesis de Laborde es que un Estado liberal es compatible con una variedad de arreglos institucionales. El liberalismo no exige expulsar a la religión de la vida pública. A los Estados liberales, concluye Laborde, les basta un secularismo de carácter minimalista. Una vez cumplidos los requisitos de

por Dios Nuestro Señor y por estos Santos Evangelios que, en ejercicio de vuestro ministerio, guardaréis la Constitución y las leyes de la República?», para agregar luego que «si así lo hiciereis, Dios os ayude, y si no, os lo demande». Los firmantes del proyecto proponen cambiarla a «jjuráis o prometéis que, en ejercicio de vuestro ministerio, guardaréis la Constitución y las leyes de la República?», a lo que el interrogado responderá «sí, juro»o «sí, prometo», dependiendo de sus creencias. A la fecha, aun no se completa el trámite legislativo y el COT sigue manteniendo la fórmula original. 
ese secularismo minimalista, no habría inconveniente — desde la perspectiva liberal- para acomodar diversas expresiones religiosas en la vida pública. Para saber cuáles son los requisitos de ese secularismo minimalista, sugiere Laborde, no sirve tratar a la religión como una entidad indivisible. En ese sentido, presta cuidadosa atención a las críticas de autores que han acusado al liberalismo de trabajar con una noción de religión típicamente occidental, basada en el modelo protestante para el cual la creencia es interior, personal y voluntaria. La noción de religión a secas, sostiene Laborde, no sirve como categoría político-legal. De ahí su estrategia interpretativa de desagregar religión en sus distintas dimensiones o, al menos, en aquellas dimensiones que son potencialmente problemáticas para el liberalismo.

En este contexto, Laborde identifica cuatro valores centrales del pensamiento liberal: primero, el Estado liberal hace descansar su legitimidad en la capacidad de justificar sus normas -Estado justificable-; segundo, el Estado liberal asegura la igualdad de estatus entre los ciudadanos -Estado inclusivo-; tercero, el Estado liberal respeta la autonomía de los individuos y, en consecuencia, circunscribe su poder coercitivo - Estado limitado-; cuarto, el Estado liberal es un Estado democrático que decide sobre su propia competencia -Estado soberano-. Cada uno de estos valores se ve amenazado por una dimensión particular del fenómeno religioso, pero no por la religión a secas.

En primer lugar, el imperativo justificatorio se debilita si los agentes del Estado — de legisladores a jueces- fundamentan normas coercitivas a partir de razones que no son accesibles al resto de los ciudadanos, de ahí que los liberales suelan abogar por el uso de razones públicas como una forma de tratar a los conciudadanos con respeto. Mientras John Rawls (2005) lo llamó un deber de civilidad, Jürgen Habermas (2006) se refirió a la misma idea como una ética de ciudadanía. Que una razón sea pública no significa que determinará automáticamente el contenido de una norma, solo significa que satisface las condiciones de admisibilidad del debate democrático. ${ }^{5}$ Razones públicas son razones epistemológicamente accesibles. Argumentar desde el dogma religioso o desde la revelación divina, en cambio, es ofrecer razones inaccesibles para aquellos que no comparten dicho dogma o no

\footnotetext{
${ }^{5}$ Comentando sobre la oposición del filósofo Michael Walzer a la eutanasia, el propio Rawls señaló que, aunque los argumentos de Walzer no le parecían convincentes, eran, no obstante, razones públicas. Éstas pueden ser buenas o malas razones, indicó. Lo importante es que puedan ser entendidas y apreciadas más allá de sus particulares doctrinas comprehensivas (Rawls, 1999, pp. 618-619).
} 


\section{Cristóbal Bellolio}

creen en tales revelaciones. En este sentido, el empleo de razones religiosas -en tanto epistemológicamente inaccesibles- para fundamentar normas coercitivas es problemático para el Estado liberal, en tano atenta contra su imperativo justificatorio.

En segundo lugar, el imperativo de inclusión se tensiona cuando la filiación religiosa constituye una marca identitaria socialmente divisiva. Para el liberalismo, todos los ciudadanos son iguales ante los ojos del poder político. Por lo mismo, cuando la religión es motivo de conflicto, un Estado que toma partido por una denominación en perjuicio de la otra está estableciendo una diferencia impermisible entre ciudadanos de primera y segunda clase. En principio, no hay problema con que los gobiernos promuevan ciertas ideas o símbolos de carácter religioso. El problema comienza cuando, a través de dicha promoción, se envía expresa o tácitamente un mensaje de exclusión. Este fue justamente el argumento que esgrimió la atea Soile Lautsi ante las cortes italianas y luego europeas: la presencia de crucifijos en las salas de clase de colegios públicos envía un mensaje de exclusión a los alumnos de familias no creyentes, como su hijo. Lautsi ganó en primera instancia ante la Corte Europea de Derechos Humanos, pero perdió en segunda. Aun así, la Corte se vio obligada a considerar que los crucifijos no eran artefactos religiosos - divisivos en el contexto de una sociedad pluralistasino culturales -inclusivos en el contexto de la identidad europea- (Case of Lautsi v. Italy. Application No. 30814/06).

En tercer lugar, la idea de un Estado limitado en su ambición de regular la totalidad de la vida de las personas peligra ante la ambición omnicomprensiva de ciertas narrativas religiosas. Esto tiene impacto sobre dos narrativas distintivamente liberales. Por un lado, como enseñaba Isaiah Berlin (2001), el liberalismo asegura la existencia de un espacioso ámbito de libertad personal —negativa - que no puede ser violado bajo pretexto alguno. De ahí la importancia de trazar un límite entre la vida privada y la autoridad pública. Muchas religiones, en cambio, aspiran a regular incluso la vida privada. Algunas Ilegan a prescribir cada detalle de la conducta humana. Esto no es necesariamente un problema para el liberalismo, en la medida que dichas obligaciones son asumidas voluntariamente por los ciudadanos, el problema aparece cuando la religión ingresa en la política y obtiene, a continuación, los medios coercitivos necesarios para imponer una sola visión sobre la vida buena. Por el otro lado, como enseñaba Kant (1996), el liberalismo se construye sobre la premisa de que el individuo 
es autónomo en su capacidad de dictarse normas morales. Cada uno es la fuente última de sus propias evaluaciones sobre lo bueno y lo malo. Varias tradiciones religiosas, en cambio, identifican la fuente última de la moralidad en un agente externo. En este sentido, la religión se asocia a un esquema ético heterónomo, en donde la decisión sobre lo bueno y lo malo escapa al individuo y queda radicada en la revelación, la doctrina o la autoridad jerárquica.

Finalmente, Laborde menciona la idea de un Estado soberano que se opone a cualquier pretensión teocrática. Un Estado liberal, en este sentido, es un Estado que tiene el poder de determinar su ámbito de jurisdicción -en terminología anglosajona, el principio de competence-competence-. Para el liberalismo es problemático que distintas agrupaciones religiosas pretendan determinar su propio ámbito de competencias, por ejemplo, dándose reglas internas que desconocen o contravienen la normativa general. Esto no quiere decir que las organizaciones religiosas no puedan gozar de ciertos grados de autonomía. Sin ir más lejos, las mujeres sufren obvias discriminaciones en el acceso a la jerarquía de la Iglesia católica, pero dichas discriminaciones son toleradas por el poder político en nombre de la independencia organizacional que gozan las asociaciones en el marco de una sociedad pluralista. Lo que dichas asociaciones no pueden hacer, en cambio, es afirmar un derecho unilateral a definir qué áreas de su quehacer quedarán sujetas a la ley y qué áreas quedarán eximida de su cumplimiento. Las reglas sobre las distintas competencias las toma el Estado democrático secular.

Laborde identifica al mismo tiempo, respecto de cada una de estas amenazas religiosas al Estado liberal, un equivalente no-religioso o secular. Así, por ejemplo, apelar a la experiencia personal, a los sueños de anoche o a las cartas del Tarot resulta tan epistémicamente inaccesible como apelar a la iluminación divina o a los textos sagrados. A su vez, la narrativa religiosa podría contener elementos perfectamente accesibles en el contexto de la deliberación democrática. Respecto del segundo criterio, Laborde advierte que las nociones de raza o clase han sido históricamente tan divisivas como la filiación religiosa. Del mismo modo en que el Estado inclusivo debe abstenerse de promover un tipo de religiosidad en detrimento de las otras, también debería abstenerse de promover una raza en perjuicio de las demás, pues en ambos casos lo relevante es no establecer ciudadanías de primera y segunda clase. Lo que corresponde, entonces, es determinar si existen 


\section{Cristóbal Bellolio}

identidades vulnerables, más allá de su carácter religioso, étnico, sexual, entre otros. En tercer lugar, la religión no es una única doctrina con ambiciones omnicomprensivas. Siguiendo a Rawls (2005), los liberales suelen referirse al kantianismo y al utilitarismo como típicas doctrinas comprehensivas seculares. En la misma categoría desfila el marxismo y ciertas versiones de humanismo cívico. Laborde añade el Ecocentrismo. Finalmente, también es posible identificar un modelo análogo a las teocracias: las ideologías políticas antidemocráticas. En todos estos casos, los valores liberales son tensionados por elementos que están presentes en ciertos discursos religiosos, pero que no son exclusivos del discurso religioso. El problema, entonces, no es la religión per se.

Este enfoque se encuentra en línea con las llamadas teorías igualitarias de la libertad religiosa: la religión no debe ser singularizada en el Estado liberal, ni para bien ni para mal, pues en muchos aspectos su función es similar a la que cumplen otras doctrinas comprehensivas o concepciones de la vida buena no-religiosas, respecto de las cuales el liberalismo también promete relacionarse en forma neutral. La religión, concluye Laborde, no es especial. Por lo anterior, propone que la idea de neutralidad sea restringida a aquellos ámbitos específicos donde los valores liberales centrales estén en riesgo. La idea de neutralidad restringida, esto es, aplicada a un determinado subconjunto de creencias, identidades y concepciones de la vida buena, está implícitamente presente en el trabajo de los teóricos igualitarios de la libertad religiosa.

Ronald Dworkin (2013) argumenta que el Estado debe ser imparcial respecto de la ética personal de los ciudadanos. Christopher Eisgruber y Lawrence Sager (2007) sostienen que el Estado no debe respaldar identidades divisivas. Jonathan Quong (2011) piensa que el Gobierno no debe promover políticas sobre las cuales los individuos manifiestan desacuerdos morales y metafísicos que denomina «fundacionales». Cada uno, reflexiona Laborde, está identificando una dimensión problemática particular del discurso religioso y sus análogos seculares: la dimensión ética —Dworkin-, la dimensión sociopolítica -Eisgruber y Sager- y la dimensión epistémica —Quong-. De una u otra forma, ya están participando de la estrategia de desagregación.

De esto se desprende que, si los valores centrales del Estado liberal -justificable, inclusivo, limitado y soberano- no están bajo amenaza, sea 
posible establecer ciertas relaciones no-neutrales con la religión. Lo que el liberalismo exige es un mínimo secular y no un estricto muro de separación. Distintos arreglos institucionales, entonces, son posibles: algunos de estos regímenes serán más progresistas y otros más conservadores; algunos serán similares al modelo de laïcité francés, mientras otros se mostrarán más abiertos a acomodar las demandas de la población religiosa.

\section{El Estado chileno frente a la estrategia de desagregación}

De acuerdo con lo anterior, no es necesario que el Estado chileno elimine todas las expresiones religiosas de la esfera pública para cumplir con los estándares seculares minimalistas que sugiere Laborde. Solo debe restringir aquellas expresiones de religiosidad que pongan en riesgo valores liberales centrales.

El primero es el imperativo de justificar sus normas a la ciudadanía a través de razones públicas. ¿Entregan razones públicas las autoridades chilenas? No siempre. Por una parte, en 2012, a propósito del debate sobre el matrimonio igualitario, el diputado democratacristiano Jorge Sabag afirmó que, si bien en sus filas había parlamentarios y precandidatos favorables a la iniciativa, él se quedaba «con la Biblia y no con lo que dicen estas importantes autoridades que no pueden pretender saber más que Dios». Agregó que le parecía sano para una sociedad «mantener el principio establecido en el Génesis que dice Varón y mujer los creó» (Leal, 2012, diciembre 6). Por otra parte, en la campaña presidencial de 2013, la candidata Evelyn Matthei señaló que se comprometía «a que no se hará nada que vaya en contra de lo que la Biblia señala: el matrimonio es entre un hombre y una mujer, y la vida se cuida desde el momento de la concepción hasta la muerte natural. No al aborto, no a la eutanasia» (El Dínamo, 2013, noviembre 25). En este caso, lo que viola el criterio del Estado justificable no es la posición sustantiva de Matthei - contra el aborto o contra la eutanasia- sino ofrecer como razón «lo que la Biblia señala». En la conformación del Congreso chileno 20182022 una reforzada bancada evangélica desafía recurrentemente el ideal liberal de razón pública liberal, y, por tanto, el criterio del Estado justificable.

Respecto del criterio de inclusión, corresponde examinar si acaso el Estado chileno envía señales que dividen a la población de acuerdo con su filiación religiosa. A diferencia de Irlanda o India, Chile no tiene una tradición de conflicto religioso. Prácticamente, no registra enfrentamientos 


\section{Cristóbal Bellolio}

violentos al respecto. El catolicismo ha sido hegemónico a lo largo de su historia independiente. A primera vista, entonces, el Estado podría acoger expresiones y desplegar mensajes de carácter religioso en la medida que estos no se consideran divisivos. Sin embargo, la correlación de fuerzas ha cambiado en las últimas décadas: crece sostenidamente la población evangélica y la población no creyente. En este nuevo escenario cabe preguntarse si acaso las señales de carácter religioso que envía el poder político siguen siendo inclusivas.

Por ejemplo, en una tradición relativamente reciente, La Moneda despliega un enorme y costoso pesebre navideño en el mes de diciembre. Inequívocamente, es un pesebre que recuerda el nacimiento de Jesús, en tanto hijo de Dios, salvador y mesías. En los últimos años, diversas organizaciones ateas chilenas han protestado por su instalación (Rivas, 2014, diciembre 11). El argumento de estas organizaciones es que el pesebre envía un mensaje de exclusión por parte de la autoridad. Parte importante de la literatura en el ámbito de la teoría política liberal coincide: las imágenes religiosas ostentosas desplegadas por el poder político en edificios públicos simbólicos — como es el caso del pesebres navideño en La Moneda-son problemáticas si se trata de transmitir la idea de igual ciudadanía (Eisgruber y Sager, 2007; Nussbaum, 2008; Taylor y Maclure, 2011; Dworkin, 2013).

Respecto del pesebre, podría rebatirse que su instalación en edificios públicos no es un endoso político, sino a una forma de reconocimiento cultural, tal como se defendió el crucifijo en Lautsi v. Italy. Sin embargo, en el enfoque de Laborde, lo problemático no es la religiosidad per se, sino el potencial divisivo del mensaje. Una expresión cultural puede ser igualmente divisiva. En consecuencia, su promoción por parte del Estado es igualmente desaconsejada. Dicho de otro modo, destacar el rol cultural, tradicional o patrimonial de un símbolo no garantiza su permisibilidad. La pregunta relevante es si acaso dicho símbolo envía un mensaje excluyente desde la autoridad a los ciudadanos respecto de cuáles son las adscripciones correctas o normales, y cuáles no.

Similares debates rodean la celebración de la Misa de Acción de Gracias - más conocida como Te Deum - de Fiestas Patrias, tanto en su versión católica como evangélica. Cada mes de septiembre, el presidente de la República y sus ministros atienden al oficio presidido por los respectivos líderes eclesiásticos, donde a veces son incluso reprendidos por sus posiciones 
en debates morales (Cooperativa.cl, 2017, septiembre 10). Grupos de ateos y no creyentes han manifestado que dicha ceremonia debe desaparecer, para dar paso a un acto genuinamente inclusivo a propósito de la celebración del aniversario de la independencia de Chile (Matamala, 2016, septiembre 16). Otro tanto se debate en torno a feriados religiosos como Corpus Christi o la Asunción de la Virgen. Es posible que en algún momento de la historia hayan sido hitos ecuménicos, en la actualidad, representan las creencias de ciertos grupos acotados de la sociedad. No es claro, en todo caso, que sean festividades divisivas en el sentido relevante, no es evidente que establezcan ciudadanías de primera y segunda categoría, por tanto, no es obvio que sean problemáticas desde el punto de vista del criterio del Estado inclusivo.

Las cosas parecen menos problemáticas en materia de Estado limitado y Estado soberano. La ambición regulatoria de la religión ha sido domesticada por la política secular. Aunque las Iglesias con presencia en Chile se movilizan para influenciar el proceso legislativo, en los últimos veinte años han sufrido repetidas derrotas: sucesivamente, las principales voces del mundo católico y evangélico se opusieron a la igualación legal de hijos nacidos dentro y fuera del matrimonio (Ley 19585 de 1998), a la derogación del delito de sodomía (Ley 19617 de 1999), al fin de la censura cinematográfica (Ley 19742 de 2001), a la ley de matrimonio civil que incluyó el divorcio (Ley 19947 de 2004), a la anticoncepción de emergencia (Ley 20418 de 2010), a la unión civil de parejas del mismo sexo (Ley 20830 de 2015), a la interrupción del embarazo en tres causales extraordinarias (Ley 21030 de 2017), a la ley de identidad de género (Ley 21120 de 2018), entre otras. Cada una de estas derrotas se traduce en mayores grados de libertad individual en el sentido liberal. En lugar de establecer coercitivamente una particular visión de la vida buena, la legislación ha puesto en manos de los ciudadanos la decisión entre distintos cursos de acción.

En conclusión, las organizaciones religiosas en Chile no tienen la capacidad de trasladar su ambición omnicomprensiva a la vida privada de las personas. Incluso en aquellos casos en los cuales Testigos de Jehová rechazan transfusiones de sangre aun cuando sus vidas están en juego, las cortes han fallado consistentemente contra dichos grupos acogiendo los recursos judiciales presentados por las unidades médicas respectivas (Diario Constitucional, 2018, agosto 2). Las Iglesias chilenas tampoco están en condiciones de desafiar la jurisdicción del Estado, que para estos efectos 
es completamente soberano. Las exenciones que reciben los templos y los fueros que gozan los altos clérigos son granjerías que otorga el Estado, el cual conserva el derecho de revocarlas. Las entidades religiosas en Chile cuentan con ciertos grados de autonomía organizacional, pero siempre sometidas a la ley general aplicable. La mayoría de los sacerdotes y obispos involucrados en casos de abuso sexual en los últimos años han comparecido ante la justicia civil y penal chilena, sin miramientos. Los procesos canónicos y las responsabilidades pastorales se canalizan en forma paralela, pero no constituyen obstáculo para que se apliquen los procedimientos comunes que empecen a todos los chilenos.

Según argumenta Laborde (2017), un Estado liberal puede coexistir con mucha o poca religión, en la medida que esas expresiones religiosas no afecten sus valores centrales. El Estado chileno, entonces, puede considerarse un Estado liberal si garantiza un mínimo secular. En lo general, ese mínimo secular parece estar asegurado, aun así, subsisten dudas en cuanto al Estado justificable y al Estado inclusivo. Respecto del primero, subsisten autoridades y legisladores que ofrecen razones religiosas que son epistémicamente inaccesibles a sus conciudadanos. Respecto del segundo, el incremento de la población no creyente debe promover una reflexión respecto de la permisibilidad de desplegar símbolos religiosos bajo el argumento de que se trata de expresiones unitarias y no divisivas.

\section{Conclusión}

En la exploración de si Chile tiene un Estado secular desde una perspectiva política, se ofrece dos enfoques de la teoría política liberal. En primer lugar, la teoría de la separación institucional entre Estado e Iglesia propuesta por Robert Audi establece tres principios para evaluar el grado de secularización de un régimen político: el libertario prescribe que los gobiernos deben permitir la práctica de cualquier culto, dentro de ciertos amplios límites; el igualitario prescribe que los gobiernos no deben preferir una religión sobre las otras; el de neutralidad prescribe que los Estados no deben favorecer o desfavorecer a la religión en cuanto tal.

En segundo lugar, el enfoque recientemente formulado por Cecile Laborde consiste en desagregar los distintos elementos del fenómeno religioso para identificar cuáles son problemáticos para el liberalismo. Las 
cualidades centrales de un Estado liberal, según Laborde, son cuatro: que sea justificable, que sea inclusivo, que sea limitado y que sea soberano. Cada una de estas características es amenazada por ciertos aspectos del discurso y la práctica religiosa, pero también por aspectos del discurso y la práctica de doctrinas seculares. En ese sentido, la religión no es enemiga del liberalismo. Lo que un Estado liberal exige es un mínimo secular que evite las expresiones problemáticas. Más allá de ese mínimo, varios arreglos institucionales son permisibles.

Respecto del enfoque de separación institucional de Audi, Estado chileno satisface el primer principio libertario - en la medida en que no genera interferencias legales a la gran mayoría de los cultos religiosos-, avanza paulatinamente con relación al segundo principio igualitario -a partir de la incorporación de capellanías en el Palacio de Gobierno y las Fuerzas Armadas, la celebración de ceremonias en edificios públicos e incluso feriados que reconocen a credos minoritarios distintos del católico一, pero queda en deuda frente al tercer principio de neutralidad, especialmente bajo gobiernos de derecha que reconocen explícitamente una vocación de promoción de la espiritualidad religiosa por sobre la ausencia de religiosidad. Es decir, el Estado chileno es solo parcialmente secular respecto de este enfoque.

Respecto del enfoque de Laborde, el Estado chileno satisface los ideales del Estado limitado y del Estado soberano: en el primer caso, porque la esfera de libertades individuales se ha expandido en las últimas décadas, haciendo retroceder a las diversas Iglesias en su pretensión regulatoria de la vida personal de los ciudadanos; en el segundo caso, porque la metacompetencia para definir las distintas competencias entre el poder temporal y el poder espiritual está radicada en el Estado democrático y no en las Iglesias. Sin embargo, el Estado chileno no cumple todos los requisitos de un Estado justificable, en la terminología de Laborde, en tanto sus autoridades y legisladores ofrecen razones religiosas no-públicas en una serie de debates de relevancia nacional, afectando la legitimidad de estas normas en el contexto de una sociedad pluralista. Del mismo modo, es discutible que el Estado chileno cumpla los requerimientos de un Estado inclusivo, toda vez que despliega y patrocina símbolos religiosos crecientemente divisivos en el marco de una sociedad que se seculariza culturalmente. 


\section{Referencias bibliográficas}

1. Argentina. Congreso. Ley 24430. (3 de enero de 1995). Constitución Nacional. Recuperado de https:/www.casarosada.gob.ar/images/stories/constitucion-nacionalargentina.pdf

2. Audi, Robert. (1989). The Separation of Church and State and the Obligations of Citizenship. Philosophy \& Public Affairs, 18 (3), pp. 259-296.

3. Audi, Robert. (2000). Religious Commitment and Secular Reason. Cambridge: Cambridge University. DOI: 10.1017/CBO9781139164528

4. Berlin, Isaiah. (2001). Dos conceptos de libertad y otros escritos. Madrid: Alianza.

5. Bhargava, Rajeev. (2006). Political Secularism. En: Dryzek, John; Honig, Bonnie \& Phillips, Anne (eds.). The Oxford Handbook of Political Theory (pp. 636-655). New York: Oxford University.

6. Barry, Brian. (2002). Culture and Equality: An Egalitarian Critique of Multiculturalism. Cambridge: Harvard University.

7. Bellolio, Cristóbal. (2014). Ateos fuera del clóset. Santiago: Penguin Random House.

8. Chile. Ministerio de Justicia. Ley 19585. (26 de octubre de 1998). Modifica el Código Civil y otros cuerpos legales en materia de filiación. Recuperado de http://

[244] bcn.cl/1uvr0

9. Chile. Ministerio de Justicia. Ley 19617. (17 de septiembre de 1999). Modifica el Código Penal, el Código de Procedimiento Penal y otros cuerpos legales en materias relativas al delito de violación. Recuperado de http://bcn.cl/1v904

10. Chile. Ministerio de Justicia. Ley 19947. (22 de octubre de 2015). Establece nueva ley de matrimonio civil. Recuperado de http://bcn.cl/1uvg1

11. Chile. Ministerio de Justicia y Derechos Humanos. Ley 21120. (10 de diciembre de 2018). Reconoce y da protección al derecho a la identidad de género. Recuperado de http://bcn.cl/284ec

12. Chile. Ministerio de Salud. Ley 20418. (2 de febrero de 2010). Fija normas sobre información, orientación y prestaciones en materia de regulación de la fertilidad. Recuperado de http://bcn.cl/1v16v

13. Chile. Ministerio de Salud. Ley 21030. (23 de septiembre de 2017). Regula la despenalización de la interrupción voluntaria del embarazo en tres causales. Recuperado de http://bcn.cl/222ky

14. Chile. Ministerio del Interior. Ley 19638. (14 de octubre de 1999). Establece normas sobre la constitución jurídica de las iglesias y organizaciones religiosas. Recuperado de http://bcn.cl/1v1v5 
15. Chile. Secretaría General de Gobierno. Ley 19742. (25 de agosto de 2001). Reforma constitucional que elimina la censura cinematográfica sustituyéndola por un sistema de calificación y que consagra el derecho a la libre creación artística. Recuperado de http://bcn.cl/1vgd3

16. Chile. Secretaria General de Gobierno. Ley 20830. (22 de octubre de 2015). Crea el acuerdo de unión civil. Recuperado de http://bcn.cl/1ux3m

17. Cooperativa.cl. (2011, diciembre 23). Presidente Piñera se definió como «creyente, aunque pecador». Recuperado de https://www.cooperativa.cl/noticias/ pais/presidente-pinera/presidente-pinera-se-definio-como-creyente-aunquepecador/2011-12-23/141326.html

18. Cooperativa.cl. (2013, noviembre 25). Evelyn Matthei no hará «nada en contra de lo que la Biblia señala». Recuperado de https:/www.cooperativa.cl/noticias/pais/ politica/presidenciales/evelyn-matthei-no-hara-nada-en-contra-de-lo-que-la-bibliasenala/2013-11-25/072701.html

19. Cooperativa.cl. (2017, septiembre 10). Presidenta Bachelet enfrentó gritos y ataques en Te Deum evangélico. Recuperado de https://www.cooperativa.cl/noticias/ pais/michelle-bachelet/presidenta-bachelet-enfrento-gritos-y-ataques-en-te-deumevangelico/2017-09-10/132657.html

20. Corral, Hernán. (1998). Iglesia católica y Estado en el ordenamiento jurídico chileno. Ius Publicum, 1, pp. 69-79.

21. Dennett, Daniel. (2006). Breaking the Spell: Religion as a Natural Phenomenon. New York: Penguin Group.

22. Diario Constitucional. (2018, agosto 2). CS ratifica fallo que acogió recurso de protección por paciente que rechaza transfusión de sangre. Recuperado de https:// www.diarioconstitucional.cl/noticias/asuntos-de-interes-publico/2018/08/02/csratifica-fallo-que-acogio-recurso-de-proteccion-por-paciente-que-rechaza-transfusionde-sangre/

23. Diaz, Lina. (2006). Fuerzas Armadas, moral y religión. El caso chileno. Estudios de Defensa, 17. Recuperado de https://www.cienciapolitica.uc.cl/images/ stories/investigacion/def17.pdf

24. Dworkin, Ronald. (2013). Religion without God. Cambridge: Harvard University.

25. Eisgruber, Christopher \& Sager, Lawrence. (2007). Religious freedom and the constitution. Cambridge: Harvard University. DOI: 10.4159/9780674034457

26. Ejército de Chile. [@Ejercito_Chile]. (2019, julio 19). Desde hace, 209 años conmemoramos a nuestra «Patrona y Generalísima de las Fuerzas Armadas de Chile» La Santa Virgen del Carmen Patrimonio de nuestra Historia y guía de la espiritualidad de los soldados [Actualización de Twitter]. Recuperado de https://twitter.com/Ejercito_ Chile/status/1151099336664784901

27. El Dínamo. (2013, noviembre 25). La promesa de Evelyn Matthei: «No haré nada que vaya en contra de la Biblia». Recuperado de https://www.eldinamo. 
cl/pais/2013/11/25/la-promesa-de-evelyn-matthei-no-hare-que-vaya-en-contra-de-labiblia/

28. Emol. (2016, octubre 11). Camila Vallejo: «No fuimos elegidos para legislar en nombre de Dios, sino por nuestros principios». Recuperado de https://www.emol. com/noticias/Nacional/2016/10/11/825998/Camila-Vallejo-No-fuimos-elegidos-paralegislar-en-nombre-de-Dios-sino-por-nuestros-principios.html

29. Escobar, Fabián. (2009, octubre 23). Uniformados evangélicos: El lento camino de la igualdad religiosa. Puro Periodismo. Recuperado de http://www. puroperiodismo.cl/?p $=2773$

30. European Court of Human Rights. Application No. 30814/06. (3 November 2009). Case of Lautsi v. Italy. Retrieved from https://hudoc.echr.coe.int/eng\#\{\%22ite $\operatorname{mid} \% 22:[\% 22001-95589 \% 22]\}$

31. Gill, Anthony. (2006). Religión y democracia en Sudamérica. Desafíos y oportunidades. En: Jelen, Ted G. \& Wilcox, Clyde (eds.). Religión y política: una perspectiva comparada. Madrid: Akal.

32. Habermas, Jürgen. (2006). Religion in the Public Sphere. European Journal of Philosophy, 14 (1), pp. 1-25. DOI: 10.1111/j.1468-0378.2006.00241.x

33. Hitchens, Christopher. (2009). Dios no existe. Lecturas esenciales para el no creyente. Barcelona: Random House Mondadori.

34. Kant, Immanuel. (1996). Practical Philosophy. The Cambridge Edition of the Works of Immanuel Kant. Cambridge: Cambridge University. DOI: 10.1017/

\section{[246] CBO9780511813306}

35. Kukathas, Chandran. (1992). Are there any cultural rights? Political Theory, 20 (1), pp. 105-139. DOI: 10.1177/0090591792020001006

36. Laborde, Cecile. (2017). Liberalism's Religion. Cambridge: Harvard University. DOI: 10.4159/9780674981560

37. Latinobarómetro. (2018, enero). El Papa Francisco y la religión en Chile y América Latina. Latinobarómetro 1995-2017. Recuperado de http://www. latinobarometro.org/latNewsShow.jsp

38. Leal, Christian. (2012, diciembre 6). Diputado Sabag (DC) contra el matrimonio homosexual: "Las autoridades no saben más que Dios». BioBioChile. Recuperado de https://www.biobiochile.cl/noticias/2012/12/06/diputado-sabag-dccontra-el-matrimonio-homosexual-las-autoridades-no-saben-mas-que-dios.shtml

39. Lincoln, Bruce. (2006). Bush's God Talk. En: de Vries, Hent \& Sullivan, Lawrence (eds.). Political Theologies: Public Religions in a Post-Secular World (pp. 269-277). New York: Fordham University.

40. Matamala, Daniel. (2016, septiembre 16). Requiem para el Te Deum. Ciper Chile. Recuperado de https://ciperchile.cl/2016/09/16/requiem-para-el-te-deum/

41. McConnell, Michael. (2000). The Problem of Singling Out Religion. DePaul Law Review, 50 (1). Retrieved from https://via.library.depaul.edu/law-review/vol50/ iss $1 / 2$ 
42. Nussbaum, Martha. (2008). Liberty of Conscience: In Defense of America's Tradition of Religious Equality. New York: Basic.

43. Precht, Jorge. (2006). 15 Estudios sobre Libertad Religiosa en Chile. Santiago: Universidad Católica de Chile.

44. Quong, Jonathan. (2011). Liberalism Without Perfection. New York: Oxford University. DOI: 10.1093/acprof:oso/9780199594870.001.0001

45. Rawls, John. (2005). Political Liberalism. New York: Columbia University.

46. Rawls, John. (1999). Collected Papers. Cambridge: Harvard University.

47. Rivas, Francisca. (2014, diciembre 11). Ateos rechazan millonario pesebre instalado en La Moneda y acusan «mal uso de recursos públicos». BioBioChile. Recuperado de https://www.biobiochile.cl/noticias/2014/12/11/ateos-rechazanmillonario-pesebre-instalado-en-la-moneda-y-acusan-mal-uso-de-recursos-publicos. shtml?fb_comment_id=754633914610765_755732144500942

48. Salinas, Carlos. (2004). Lecciones de derecho eclesiástico del Estado de Chile. Valparaíso: Pontificia Universidad Católica de Valparaíso.

49. Serrano, Sol. (2008). ¿Qué hacer con Dios en la República? Política y secularización en Chile 1845-1885. Santiago: Fondo de Cultura Económica.

50. Silva, Alejandro y Silva, María Pía. (1991). Personalidad jurídica de las Iglesias. Revista Chilena de Derecho, 18 (1), pp. 61-71.

51. Sullivan, Winnifred Fallers. (2005). The Impossibility of Religious Freedom. Princeton and Oxford: Princeton University.

52. Taylor, Charles. (2007). A Secular Age. Cambridge and London: The Belknap.

53. Taylor, Charles \& Maclure, Jocelyne. (2011). Secularism and Freedom of Conscience. Cambridge and London: Harvard University. 